\title{
Why do thioureas and squaramides slow down the Ireland-Claisen rearrangement?
}

\author{
Dominika Krištofíková $^{1}$, Juraj Filo², Mária Mečiarová ${ }^{* 1}$ and Radovan Šebesta*1
}

\author{
Full Research Paper \\ Address: \\ ${ }^{1}$ Department of Organic Chemistry, Faculty of Natural Sciences, \\ Comenius University in Bratislava, Mlynská dolina, Ilkovičova 6, \\ 84215 Bratislava, Slovakia and ${ }^{2}$ Institute of Chemistry, Faculty of \\ Natural Sciences, Comenius University in Bratislava, Mlynská dolina, \\ Ilkovičova 6, 84215 Bratislava, Slovakia \\ Email: \\ Mária Mečiarová* - maria.meciarova@uniba.sk; Radovan Šebesta* - \\ radovan.sebesta@uniba.sk \\ * Corresponding author \\ Keywords: \\ DFT calculations; green solvents; $\mathrm{H}$-bonding catalysts; \\ Ireland-Claisen rearrangement; silyl ketene acetals \\ Beilstein J. Org. Chem. 2019, 15, 2948-2957. \\ doi:10.3762/bjoc. 15.290 \\ Received: 28 May 2019 \\ Accepted: 25 November 2019 \\ Published: 10 December 2019 \\ Associate Editor: M. Rueping \\ (C) 2019 Krištofíková et al.; licensee Beilstein-Institut. \\ License and terms: see end of document.
}

\begin{abstract}
A range of chiral hydrogen-bond-donating organocatalysts was tested in the Ireland-Claisen rearrangement of silyl ketene acetals. None of these organocatalysts was able to impart any enantioselectivity on the rearrangements. Furthermore, these organocatalysts slowed down the Ireland-Claisen rearrangement in comparison to an uncatalyzed reaction. The catalyst-free reaction proceeded well in green solvents or without any solvent. DFT calculations showed that the activation barriers are higher for reactions involving hydrogen-donating organocatalysts and kinetic experiments suggest that the catalysts bind stronger to the starting silyl ketene acetals than to transition structures thus leading to inefficient rearrangement reactions.
\end{abstract}

\section{Introduction}

The Ireland-Claisen rearrangement is a reaction converting allyl esters to $\gamma, \delta$-unsaturated carboxylic acids. Its key step is a [3,3]-sigmatropic rearrangement of a silyl ketene acetal, which is generated in situ by deprotonation of an allyl ester using a strong base [1-3]. The products of the Ireland-Claisen rearrangement, $\gamma, \delta$-unsaturated acids, are useful precursors of biologically active compounds and natural products [4-11]. The ready availability of allylic esters, the ability to control the $E / Z$ geometry of enolates as well as its stereospecificity make this transformation synthetically appealing $[12,13]$.

Allyl esters of various carboxylic acids undergo rearrangement as their lithium enolates or silyl ketene acetals and the corresponding acids were isolated in $75-80 \%$ yields. Accordingly, the Ireland-Claisen rearrangement of lithium enolates generated from allyl fluoroacetates gave the corresponding $\alpha$-fluoro- 
$\gamma, \delta$-unsaturated acids [14]. The Ireland-Claisen rearrangement of $\mathrm{Et}_{3} \mathrm{~N}$-solvated enolates showed higher reactivity as well as diastereoselectivity when compared with analogous reactions in THF [15].

The required ester enolates are typically generated using a strong base, such as LDA or similar amides in combination with trialkylsilyl chlorides as silylating agents at low temperature under strictly anhydrous conditions $[3,16,17]$. An alternative method employs tertiary amines as bases in combination with more reactive silylating agents, such as trialkylsilyl triflates $[18,19]$.

The rearrangement of ester enolates generated by LDA with metal ions bearing bulky cyclopentadienyl ligands proceeded well with yields of up to $90 \%$, and diastereomeric ratios strongly depended on the ligands used [20]. The presence of catalytic amounts of Lewis acids improved the diastereoselectivity and the reaction rate of silyl ketene acetals of $(E)$-allylic esters [21]. Chiral bromoboranes were used to form boranyl ketene acetals from ester enolates generated from allyl esters with tertiary amines. The geometry of the enolates depended strongly on the solvent and the amine's structure [22,23].

The decomposition of the enolate is one of the side reactions, which can be suppressed by chelation. The chelation-stabilized enolates are more stable than the corresponding silyl ketene acetals, and they are capable of a direct rearrangement [24]. The chelation-controlled Ireland-Claisen rearrangement of $O$-protected allylic glycolate esters proceeded with moderate yields and diastereoselectivities of up to 20:1 [25]. An asymmetric ester-enolate-Claisen rearrangement was achieved by using aluminum-chelate-bridged enolates and proceeded with high yields and diastereoselectivities, and ees up to $86 \%$ [26]. Rearrangement of allyl esters of glycine derivatives gave under similar conditions amino acids with a quaternary stereocenter on the $\beta$-carbon with high yields and excellent diastereo- as well as enantioselectivity [5]. A reductive rearrangement of allyl esters of acrylic acid, catalyzed by in situ-generated copper hydride with diethoxymethylsilane as a reductive agent gave the $\gamma, \delta$-unsaturated acid with good to excellent diastereoselectivities [27].

Various asymmetric organocatalyzed rearrangements are known [28]. However, the catalysis of sigmatropic rearrangements is difficult due to their rather nonpolar transition states, which are difficult to be addressed by catalysts [29]. Several stereoselective [3,3]-sigmatropic rearrangements are realized with chiral Brønsted acids [30-34]. Jacobsen reported guanidinium-catalyzed enantioselective Claisen rearrangements of $O$-allyl $\beta$-ketoesters [35-37]. Hiersemann and Strassner studied the Claisen rearrangement with H-bond-donating organocatalysts by computational methods and concluded that thioureas are not efficient in transition-state stabilization [38].

Regarding the usefulness of the Ireland-Claisen rearrangement, we tried to optimize its reaction course under mild conditions using various bases, solvents, and hydrogen-bond-donating catalysts. We also present a computational explanation and NMR kinetic study for the inefficient Ireland-Claisen rearrangement under thiourea and squaramide catalysis.

\section{Results and Discussion}

We started our investigation with the rearrangement of trimethylsilyl ketene acetal (2a) derived from allyl propionate (1a, Scheme 1). Silyl ketene acetals 2 can be observed by NMR in the reaction mixture (see Supporting Information File 1 for NMR spectra of 2c). This reaction afforded the corresponding acid 3a in 63\% yield at rt (Table 1, entry 1). At a higher temperature, the product yield decreased (Table 1, entry 2 ). The reaction of the related $(E)$-but-2-en-1-yl propionate $(\mathbf{1 b})$ gave acid 3b under similar conditions with slightly lower yields. The rearrangement of lithium enolate, as well as trimethylsilyl ketene

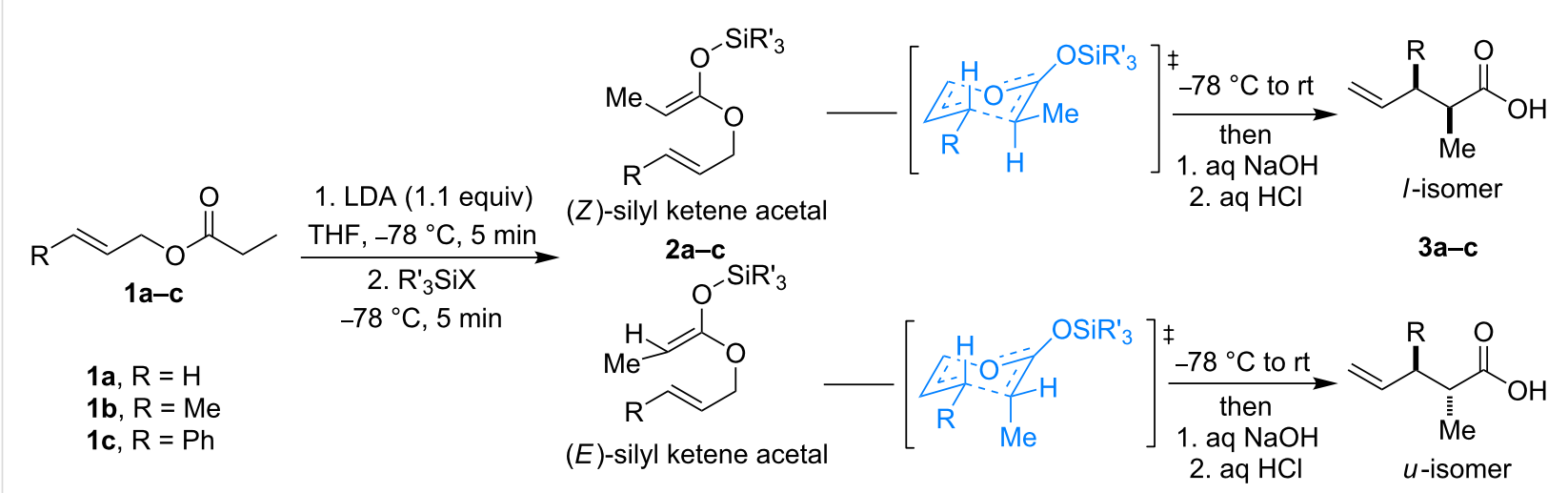




\begin{tabular}{|c|c|c|c|c|c|c|}
\hline Entry & $\mathrm{R}$ & $\mathrm{R}_{3}{ }_{3} \mathrm{SiX}$ (equiv) & Temperature $\left({ }^{\circ} \mathrm{C}\right)$ & Time $(h)$ & Yield of 2 (\%) & $d r$ \\
\hline 1 & $\mathrm{H}$ & $\mathrm{Me}_{3} \mathrm{SiCl}(1.1)$ & rt & 168 & 63 & - \\
\hline 2 & $\mathrm{H}$ & $\mathrm{Me}_{3} \mathrm{SiCl}(1.1)$ & 66 & 3 & 41 & - \\
\hline 3 & $\mathrm{Me}$ & $\mathrm{Me}_{3} \mathrm{SiCl}(1.1)$ & rt & 72 & 42 & $76: 24$ \\
\hline 4 & $\mathrm{Me}$ & $\mathrm{Me}_{3} \mathrm{SiCl}(1.1)$ & 66 & 2 & 36 & $76: 24$ \\
\hline 5 & $\mathrm{Me}$ & $\mathrm{Me}_{3} \mathrm{SiCl}(1.1)$ & rt & 20 & 38 & $77: 23$ \\
\hline 6 & $\mathrm{Me}$ & - & $\mathrm{rt}$ & 20 & 30 & $79: 21$ \\
\hline 7 & $\mathrm{Ph}$ & $\mathrm{Me}_{3} \mathrm{SiCl}(1.0)$ & $\mathrm{rt}$ & 168 & 0 & - \\
\hline 8 & $\mathrm{Ph}$ & $t-\mathrm{BuMe}_{2} \mathrm{SiOTf}(1.1)$ & rt & 168 & 0 & - \\
\hline
\end{tabular}

acetal $\mathbf{2 b}$ generated from $\mathbf{1 b}$, proceeded with similar yields and diastereoselectivity (Table 1, entries 3-6). However, the Ireland-Claisen rearrangement attempted with cinnamyl propionate (1c) did not take place when using LDA as a base (Table 1, entries 7 and 8).

Next, we studied the Ireland-Claisen rearrangement of ester 1c using various tertiary amines as bases. The ester enolate was trapped with $\mathrm{Me}_{3} \mathrm{SiOTf}$ at $-60{ }^{\circ} \mathrm{C}$ and allowing the reaction to proceed at room temperature for $24 \mathrm{~h}$. The best yields of acid $\mathbf{3 c}$ were achieved with triethylamine (74\%) and $\mathrm{N}$-cyclohexyl- $\mathrm{N}$ methylcyclohexanamine $(65 \%$, Scheme 2$)$ whereas reactions with trihexylamine and diisopropylethylamine provided the product $3 \mathbf{c}$ with lower yields. Rearrangement in the presence of $N$-methylmorpholine, quinine, and $N$-methylpyrrolidine afforded only traces of acid $\mathbf{3 c}$ and reactions with DBU, DABCO and (S)-1-(pyrrolidin-2-ylmethyl)pyrrolidine did not proceed at all. Of note, the bases used in these Ireland-Claisen rearrangements did not affect the diastereoselectivity and the syn/anti ratio was approximately 70:30 in all cases.

The Ireland-Claisen rearrangement of allyl propionate (1a) with $\mathrm{Et}_{3} \mathrm{~N}$ and $\mathrm{Me}_{3}$ SiOTf afforded 2-methylpent-4-enoic acid (3a) in $75 \%$ yield. However, the yield of product 3a dropped to $22 \%$ when the reaction was performed at $40{ }^{\circ} \mathrm{C}$. The rearrangement of $\mathbf{1 a}$ with $t$-BuMe $\mathrm{Bu}_{2}$ SiOTf gave only $40 \%$ of acid $\mathbf{3 a}$ (Table 2 ,

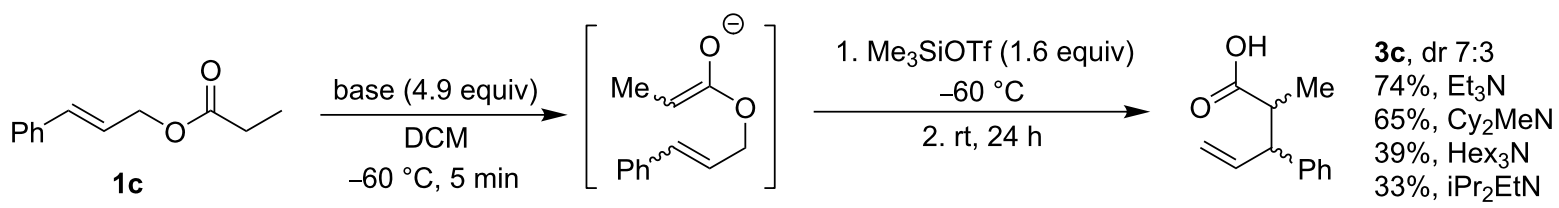

Scheme 2: Ireland-Claisen rearrangement of 1c mediated by tertiary amines.

Table 2: Ireland-Claisen rearrangement with $\mathrm{Et}_{3} \mathrm{~N}$ as a base.

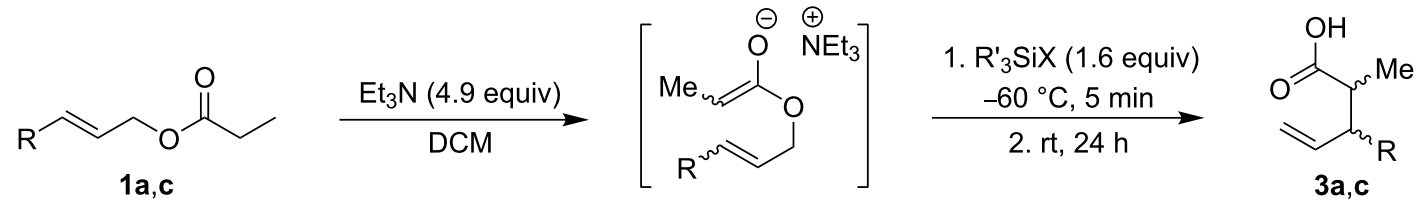

1a, 3a $R=H ; 1 c, 3 c R=P h$

\begin{tabular}{lllllll}
\hline Entry & $\mathrm{R}$ & $\mathrm{R}_{3}{ }_{3} \mathrm{SiOTf}$ & $T\left({ }^{\circ} \mathrm{C}\right)$ & $t(\mathrm{~h})$ & Yield of 3 $(\%)$ & $\mathrm{dr}$ \\
\hline 1 & $\mathrm{H}$ & $\mathrm{Me}_{3} \mathrm{SiOTf}$ & $\mathrm{rt}$ & 24 & 75 & - \\
2 & $\mathrm{H}$ & $\mathrm{Me}_{3} \mathrm{SiOTf}$ & 40 & 4 & 22 & - \\
3 & $\mathrm{H}$ & $t$-BuMe $\mathrm{BuOTf}_{2}$ & $\mathrm{rt}$ & 24 & 40 & $69: 31$ \\
4 & $\mathrm{Ph}$ & $\mathrm{Me}_{3} \mathrm{SiOTf} \mathrm{rt}$ & 5 & 24 & 74 & $71: 29$ \\
5 & $\mathrm{Ph}$ & $\mathrm{Me}_{3} \mathrm{SiOTf}$ & 5 & 72 & 50 & -
\end{tabular}


entries 1-3). The yield of acid $3 \mathbf{c}$ decreased from 74 to $50 \%$ when the reaction was performed at $5{ }^{\circ} \mathrm{C}$ (Table 2, cf. entries 4 and 5) and the reaction temperature did not affect the diastereoselectivity of the reaction. No product $\mathbf{3 c}$ was obtained when the reaction was performed without silyl triflate (Table 2, entry 6).

We assumed that hydrogen-bond-donating organocatalysts could activate the enolates or the corresponding silyl ketene acetals or stabilize the corresponding transition states. In addition, chiral organocatalysts could induce diastereo- as well as enantioselectivity. Therefore, we examined the Ireland-Claisen rearrangement of ester $1 \mathbf{c}$ in the presence of a range of organocatalysts, including chiral squaramides, thioureas, alkaloids and their derivatives, taddols, binol, chiral phosphoric acid, $(S)$ proline and its derivatives, amide of tryptophan (Figure 1). These catalysts feature varying steric properties from sterically encumbered, such as $\mathbf{C 1}, \mathbf{C 5}, \mathbf{C 8}$, or $\mathbf{C 1 0}$, to less demanding ones, e.g., C6, C9 or C11. In addition, the acidity of the hydrogen-bond-donating moiety also ranges over a rather large area from $\mathrm{pKa}\left(\mathrm{H}_{2} \mathrm{O}\right) 1$ for phosphoric acid $\mathbf{C 1 0}$ to $\mathrm{pKa}$ (DMSO) 28 of diols $\mathbf{C 7}$ and $\mathbf{C 8}$. However, neither steric factors, nor the acidity of the $\mathrm{H}$-bond-donor moiety seemed to play a signifi- cant role in the Ireland-Claisen rearrangement of 1c. Surprisingly, all catalysts led to a decreased yield of the acid $\mathbf{3 c}$ (28-62\%) in comparison to $74 \%$ yield obtained without any chiral organocatalyst. Further, none of the chiral organocatalysts considerably affected the diastereoselectivity and acid $\mathbf{3 c}$ was obtained in racemic form in the presence of either tested chiral organocatalyst. Similar results were obtained with ester 1a. The reaction was tested also in the more polar solvent acetonitrile using catalyst $\mathbf{C 1}$, but also in this case no enantioselectivity was observed. Sigmatropic rearrangements proceed via isopolar transition states and, therefore solvent effects are rather small. For this reason and due to the complete lack of enantioselectivity, at this stage, we did not investigate other solvents with the catalysts collected in Figure 1.

In order to gain further insight into the catalyst's action in the rearrangement, we have studied the effect of catalyst loading in the reaction of ester $\mathbf{1 c}$ with squaramide $\mathbf{C 1}$. The reaction with $\mathrm{Et}_{3} \mathrm{~N}$ as a base and $\mathrm{Me}_{3} \mathrm{SiOTf}$ without any chiral organocatalyst afforded acid $\mathbf{3 c}$ with $74 \%$ yield. Repeating the reaction in the presence of squaramide C1 (5 mol \%) lowered the yield from 74 to $37 \%$. A similar yield (35\%) was achieved with<smiles>C=CC1CN2CCC1C2[C@H](Nc1c(Nc2cc(C(F)(F)F)cc(C(F)(F)F)c2)c(=O)c1=O)c1ccnc2ccc(OC)cc12</smiles>
$35 \%(63: 37)$<smiles>C=CC1CN2CCC1CN2[C@H](NC(=S)Nc1cc(C(F)(F)F)cc(C(F)(F)F)c1)c1ccnc2ccc(OC)cc12</smiles>
$40 \%(70: 30)$<smiles>Oc1ccc2ccccc2c1-c1c(O)ccc2ccccc12</smiles>

C9

$40 \%(71: 29)$<smiles>CC(C)[CH+]c1cc2ccccc2cc1OP(=O)(O)Oc1c([CH+]C(C)C)cc2ccccc2c1-c1c(OP(=O)(O)O)c([SnH2]CC(C)C)cc2ccccc12</smiles>

C10<smiles>CC(NS(=O)(=O)NC(C)c1ccccc1)c1ccccc1</smiles>

C6<smiles>CC1([Cl+])CC(C(O)(c2ccccc2)c2ccccc2)C(C(O)(c2ccccc2)c2ccccc2)O1</smiles>

$46 \%(71: 29)$

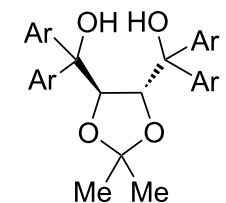

C8 $(\mathrm{Ar}=2$-naphthyl) $45 \%(71: 29)$

Figure 1: Organocatalysts used in this study. Conditions: typical procedure: $1 . \mathrm{Et}_{3} \mathrm{~N}$ (4.9 equiv), DCM, $-60{ }^{\circ} \mathrm{C}, 5 \mathrm{~min} ; 2 . \mathrm{Me}_{3} \mathrm{SiOTf}(1.6$ equiv), catalyst $(10 \mathrm{~mol} \%),-60{ }^{\circ} \mathrm{C} ; 3 . \mathrm{rt}, 24 \mathrm{~h}$. 
$10 \mathrm{~mol} \%$ of $\mathbf{C 1}$ (Table 3, entries 1-3) and further increasing the catalyst loading to 20 and $30 \mathrm{~mol} \%$ diminished the product yield even more ( 26 and $21 \%$, respectively; Table 3, entries 4 and 5). Ultimately, one equivalent of squaramide $\mathbf{C} 1$ completely stopped the reaction (Table 3, entry 6).

Table 3: Effect of catalyst loading on the Ireland-Claisen rearrangement of 1c.

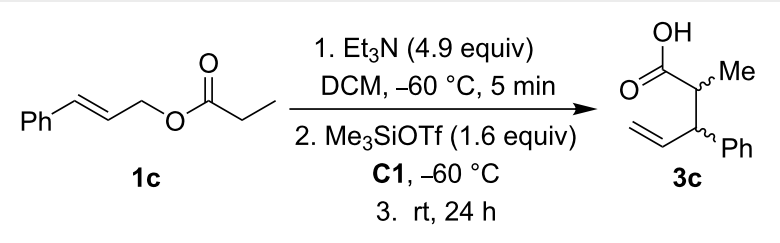

\begin{tabular}{llll}
\hline Entry & $\mathbf{C 1}(\mathrm{mol} \%)$ & Yield of 3c (\%) & syn/anti \\
\hline 1 & 0 & 74 & $69: 31$ \\
2 & 5 & 37 & $71: 29$ \\
3 & 10 & 35 & $63: 37$ \\
4 & 20 & 26 & $74: 26$ \\
5 & 30 & 21 & $75: 25$ \\
6 & 100 & 0 & -
\end{tabular}

We also studied the effect of the amount of base on the Ireland-Claisen rearrangement of ester $\mathbf{1 c}$ in the presence of sulfanediamine C6 (Table 4). The best yield of acid 3c (74\%) was recorded with 4.9 equivalents of $\mathrm{Et}_{3} \mathrm{~N}$ without chiral organocatalyst. The yield of acid $3 \mathbf{c}$ decreased to $62 \%$ in the presence of $10 \mathrm{~mol} \%$ of C6. An even higher amount of base did not improve the yield of acid $3 \mathbf{c}$ (Table 4 , entry 3 ). The reaction with 2.5 equivalents of $\mathrm{Et}_{3} \mathrm{~N}$ gave $51 \%$ of acid $3 \mathbf{c}$. Also here, both diastereomers were obtained as racemates.

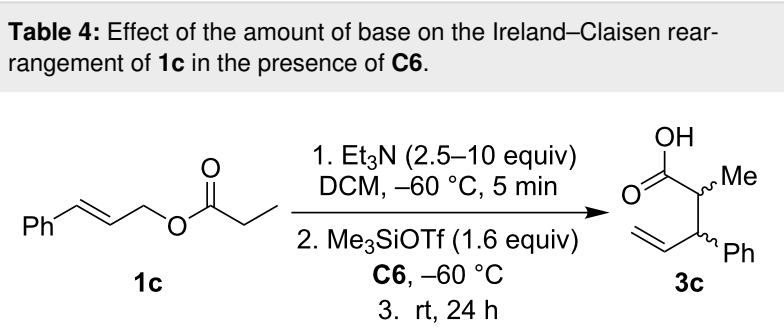

\begin{tabular}{lllll}
\hline Entry & $\mathrm{Et}_{3} \mathrm{~N}$ (equiv) & $\mathbf{C 6}(\mathrm{mol} \%)$ & Yield of 3c (\%) & syn/anti \\
\hline 1 & 4.9 & 0 & 74 & $69: 31$ \\
2 & 4.9 & 10 & 62 & $69: 31$ \\
3 & 10 & 10 & 70 & $71: 29$ \\
4 & 2.5 & 10 & 51 & $64: 36$
\end{tabular}

As mentioned above, the Ireland-Claisen rearrangement, as a pericyclic reaction, is expected to be rather insensitive to sol- vent effects. However, minor improvements in reaction time have been noted in some cases [39]. Therefore, with the aim of improving the reaction course, we evaluated several other solvents, emphasizing green solvents, which have not been evaluated in Ireland-Claisen rearrangements before. 2-Methyltetrahydrofuran (2-MeTHF) is derived from renewable resources and has a higher boiling point $\left(80^{\circ} \mathrm{C}\right)$ and lower heat of vaporization compared to THF. The Ireland-Claisen rearrangement proceeded in 2-MeTHF with slightly lower yield and very similar diastereoselectivity as in DCM (Table 5, entries 1 and 2). A low tendency to peroxide formation, stability under acidic and basic conditions, high boiling point, and low heat of vaporization are also positive features of cyclopentyl methyl ether (CpOMe) [40]. From the chemical yield point of view, cyclopentyl methyl ether was the best solvent for the Ireland-Claisen rearrangement of ester 1c; acid $\mathbf{3 c}$ was isolated in $84 \%$ yield. However, even in CpOMe, catalyst C6 decreased the yield of acid $\mathbf{3 c}$ to $73 \%$ (Table 5, entries 3 and 4 ). A less toxic alternative to dichloromethane is trifluorotoluene and the rearrangement of $\mathbf{1 c}$ in this solvent afforded acid $\mathbf{3 c}$ in $76 \%$ (Table 5, entry 5). Glymes are environmentally benign aprotic polar and chemically inert solvents [41]. The desired product $\mathbf{3 c}$ through Ireland-Claisen rearrangement of 1c was isolated in $58 \%$ when the reaction was carried out in dimethyl ethylene glycol (Table 5, entry 6). However, Ireland-Claisen rearrangement of ester 1c did not proceed in 2,2,2-trifluoroethanol, ethyl L-lactate or in 2-butanone.

Interestingly, the best yield of acid 3c (95\%) was obtained when the reaction was carried out without any solvent (Table 5, entry 8). Again, catalyst C6 (10 mol \%) decreased the yield under solvent-free conditions from 95 to $73 \%$ (Table 5, entries 8 vs 9).

The Ireland-Claisen rearrangement of cinnamyl isobutyrate (1d) gave under solvent-free conditions only 17\% of the acid 3d and the analogous reaction in CpOMe afforded the acid in 5\% yield. When cinnamyl butyrate (1e) was used as a starting material, product $3 \mathrm{e}$ was obtained in a yield of $60 \%$ (Scheme 3 ).

To gain further insights into the organocatalysts effect on the Ireland-Claisen rearrangement, we have performed quantumchemical calculations employing long-range corrected hybrid density $\omega$ B97X-D functional [42]. This dispersion-corrected functional displays very balanced overall performances and has demonstrated excellent treatment of noncovalent interactions [43], which are very important in our studied system. For this, we have compared the uncatalyzed Ireland-Claisen rearrangement with three hydrogen-bond-catalyzed reactions. As model H-bonding catalysts, we selected diphenylthiourea, Schreiner thiourea, and the corresponding squaramide with bis(trifluoromethyl)phenyl groups. We have evaluated both the (E)- and 
Table 5: Green solvents screening for the Ireland-Claisen rearrangement of 1c

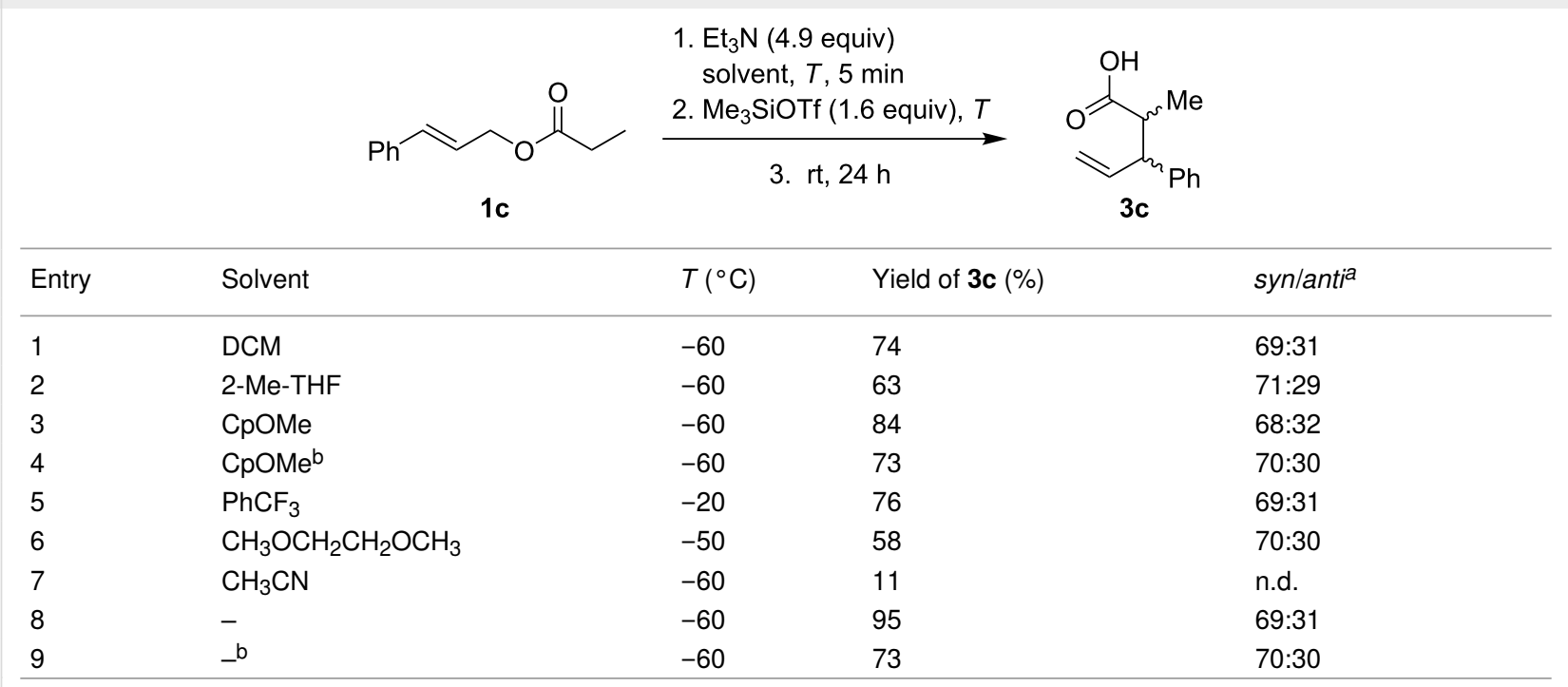

aBoth diastereomers were obtained as a racemic mixture. ${ }^{\mathrm{b}}$ Reaction carried out in the presence of $\mathbf{C 6}(10 \mathrm{~mol} \%)$.<smiles>[R]C([R])C(=O)OC/C=C/c1ccccc1</smiles>

1. $\mathrm{Et}_{3} \mathrm{~N}$ (4.9 equiv), $-60^{\circ} \mathrm{C}, 5 \mathrm{~min}$ 2. $\mathrm{Me}_{3} \mathrm{SiOTf}$ (1.6 equiv) 3. rt, $24 \mathrm{~h}$ 1c, $\mathrm{R}^{1}=\mathrm{H}, \mathrm{R}^{2}=\mathrm{Me}$

1d, $R^{1}=M e, R^{2}=M e$

1e, $R^{1}=H, R^{2}=E t$<smiles>[R]C([R])(C(=O)O)[C@H](C=C)c1ccccc1</smiles>

3c, $R^{1}=H, R^{2}=M e \quad 95 \%, d r 69: 31$

3d, $R^{1}=M e, R^{2}=M e \quad 17 \%$

3e, $R^{1}=H, R^{2}=E t \quad 60 \%$, dr $67: 33$

Scheme 3: Solvent-free Ireland-Claisen rearrangement of cinnamyl esters.

(Z)-silyl ketene acetal 2c derived from 1c as starting material for the reaction. The activation barrier for the uncatalyzed reaction of $(E)$-silyl ketene acetal was $98.5 \mathrm{~kJ} \cdot \mathrm{mol}^{-1}$, and for $(Z)$ silyl ketene acetal $88.7 \mathrm{~kJ} \cdot \mathrm{mol}^{-1}$ (Figure 2). Charges on the allylic oxygen in the reaction transition states are only slightly more negative than in the starting acetal silyl ketenes. It means that transition states have only slightly dipolar character, which would be difficult to stabilize through hydrogen bonding and consequently reaction less prone to catalysis.

Interestingly, the reaction comprising Schreiner thiourea (C12) had higher activation barriers for both isomers $\left(111.9 \mathrm{~kJ} \cdot \mathrm{mol}^{-1}\right.$ for $(E)$ and $95.6 \mathrm{~kJ} \cdot \mathrm{mol}^{-1}$ for $(Z)$ ). These results suggest that Schreiner thiourea binds stronger to starting silyl ketene acetal than to the corresponding transition state. Therefore, it stabilizes more the starting material than the transition state, which results in the slow-down of the reaction (Figure 3).

Similar trends were observed also for diphenylthiourea and a squaramide (Figure 4).
Using the structures optimized at the $\omega \mathrm{B} 97 \mathrm{X}-\mathrm{D} / 6-31 \mathrm{G}^{*}$ level of theory we calculated interaction energies between catalysts and starting silyl ketene acetals or corresponding transition state structures at the M06-2X/6-311+G** level. For the Schreiner thiourea (C12) as well as diphenylthiourea interaction energies were higher in the starting silyl ketene acetal-catalyst complexes than in the corresponding transition states. For the squaramide catalyst, these energies were similar (Table 6). These calculations further support the notion that hydrogenbonding organocatalysts bind stronger to starting silyl ketene acetals than to the transition structure and thus are not efficiently catalyzing the Ireland-Claisen rearrangement. The reason for this difference, however, remains unclear. The explanation may be connected to a more compact transition state of sigmatropic rearrangements than their starting materials, which is thus less amenable to additional stabilization via hydrogenbonding catalysts.

To get further insight, we have performed a kinetic study of the reaction using ${ }^{1} \mathrm{H}$ NMR spectroscopy. Figure 5 a shows a com- 

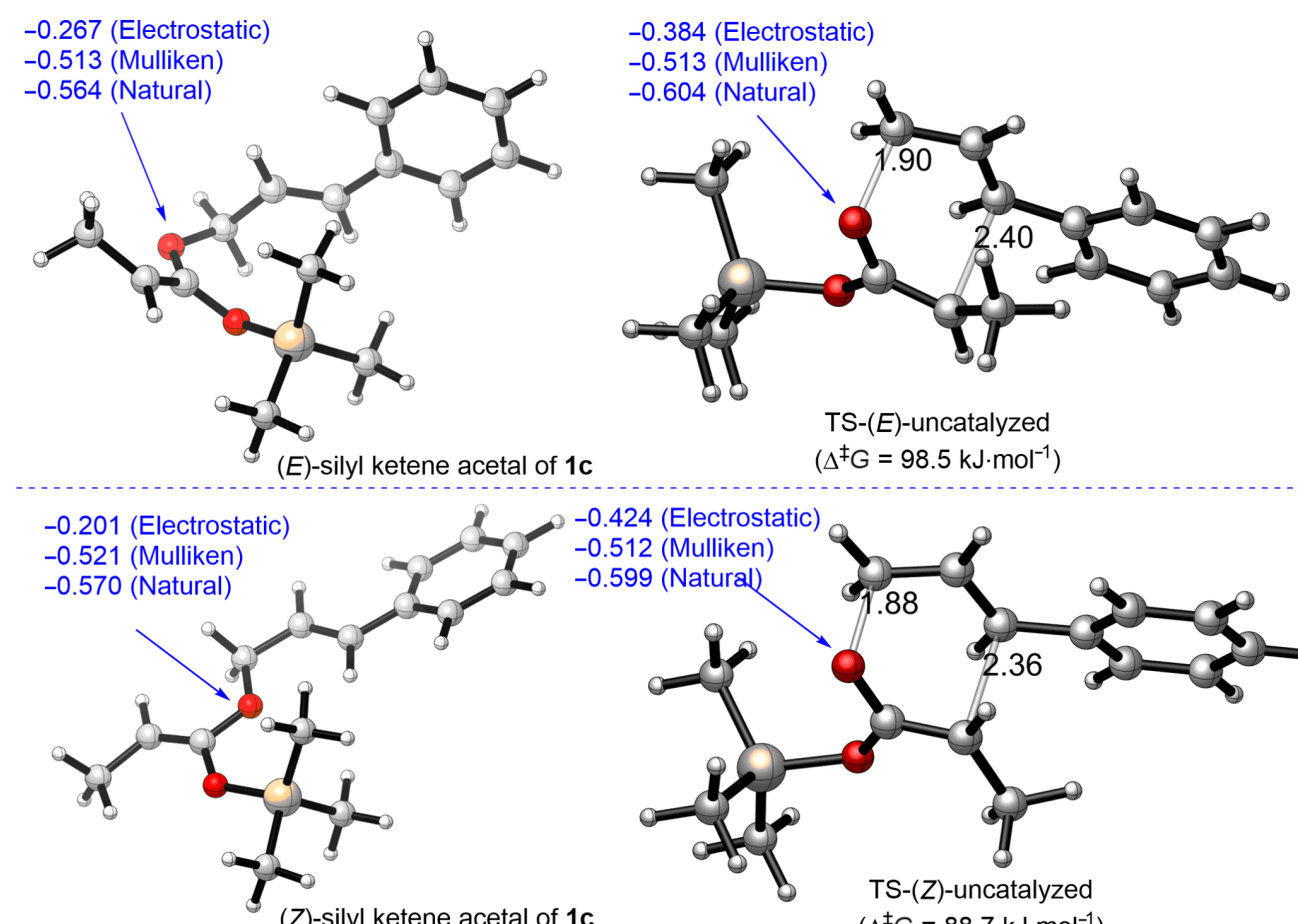

0.424 (Electrostatic)

-0.512 (Mulliken)

0.521 (Mulliken)

570 (Natural)

599 (Natural)

(Z)-silyl ketene acetal of 1c

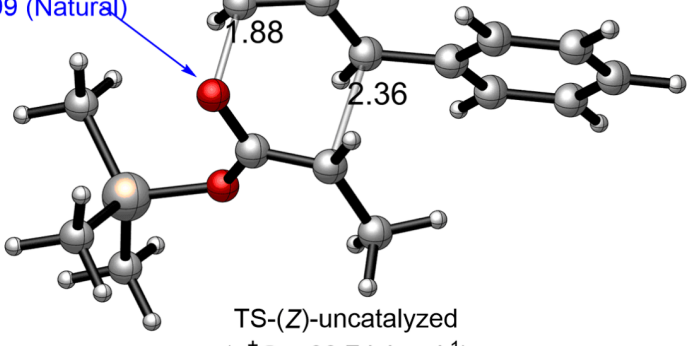

$\left(\Delta^{\ddagger} G=88.7 \mathrm{~kJ} \cdot \mathrm{mol}^{-1}\right)$

Figure 2: $\omega B$ 97X-D/6-31G* calculated uncatalyzed Ireland-Claisen rearrangement of 1c. Charges on allylic oxygen (blue); C-O bond-breaking and C-C bond-forming distances in TS (black).

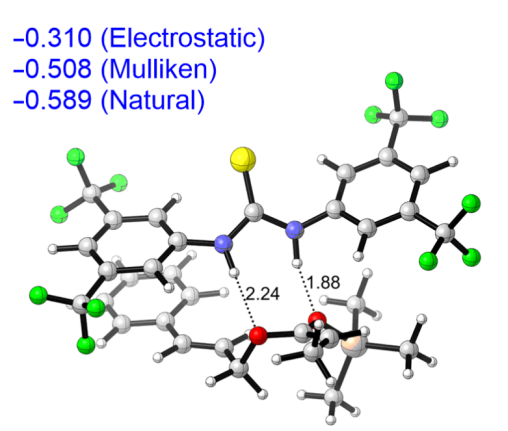

(E)-silyl ketene acetal + Schreiner thiourea

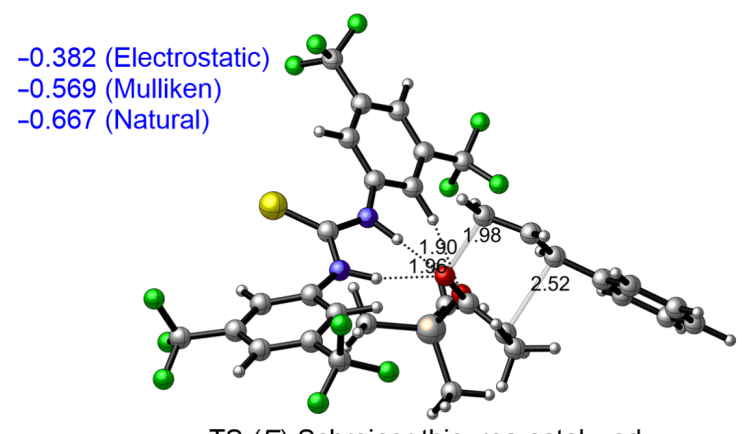

TS-(E)-Schreiner thiourea-catalyzed $\left(\Delta^{\ddagger} \mathrm{G}=111.9 \mathrm{~kJ} \cdot \mathrm{mol}^{-1}\right)$

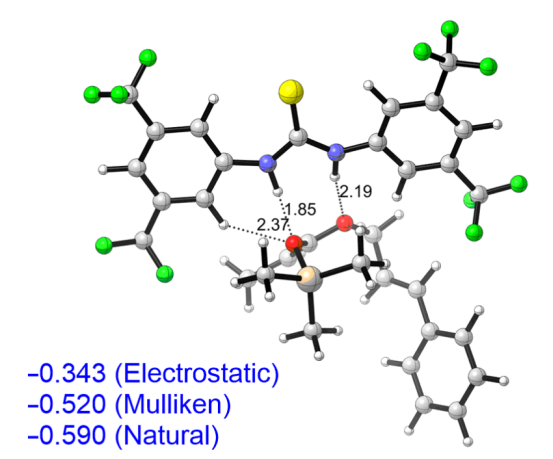

(Z)-silyl ketene acetal + Schreiner thiourea

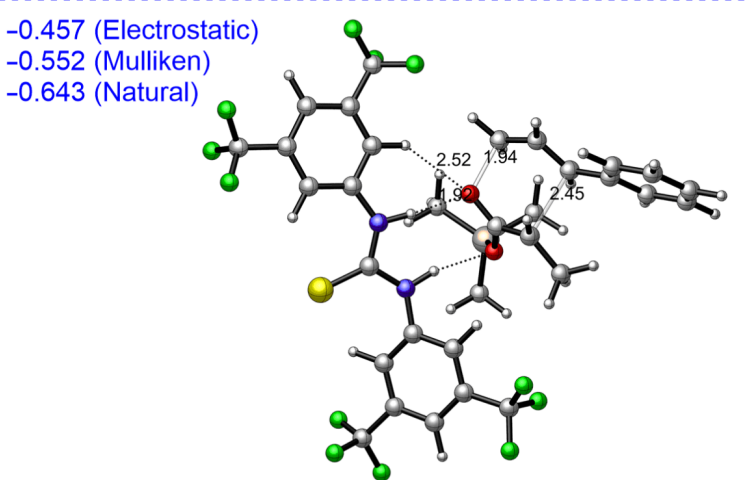

TS-(Z)-Schreiner thiourea-catalyzed $\left(\Delta^{\ddagger} \mathrm{G}=95.6 \mathrm{~kJ} \cdot \mathrm{mol}^{-1}\right)$

Figure 3: $\omega B$ 97X-D/6-31G* calculated Schreiner thiourea (12)-catalyzed Ireland-Claisen rearrangement of 1c. Charges on allylic oxygen (blue); C-O bond-breaking and $\mathrm{C}-\mathrm{C}$ bond-forming distances in TS (black); hydrogen-bond distances (black). 
-0.083 (Electrostatic)

-0.544 (Mulliken)

-0.617 (Natural)

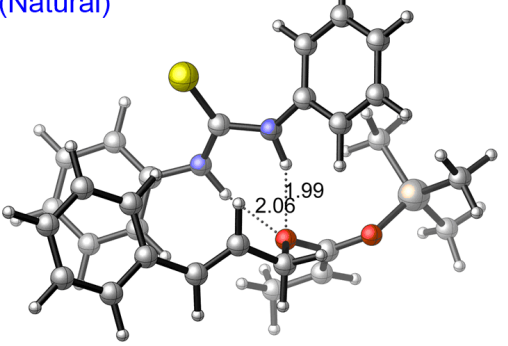

(E)-silyl ketene acetal $+\mathrm{Ph}$-thiourea

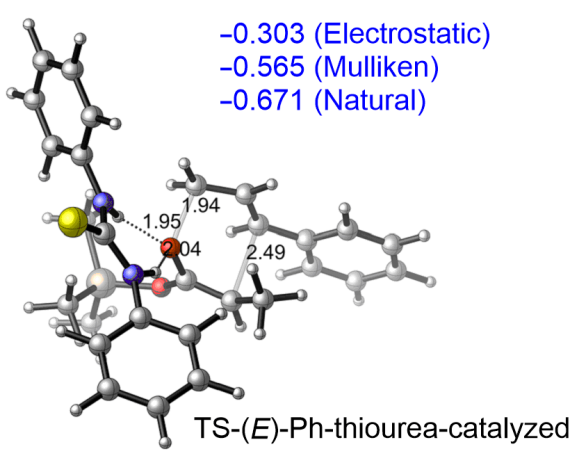

$\left(\Delta^{\ddagger} G=110.7 \mathrm{~kJ} \cdot \mathrm{mol}^{-1}\right)$

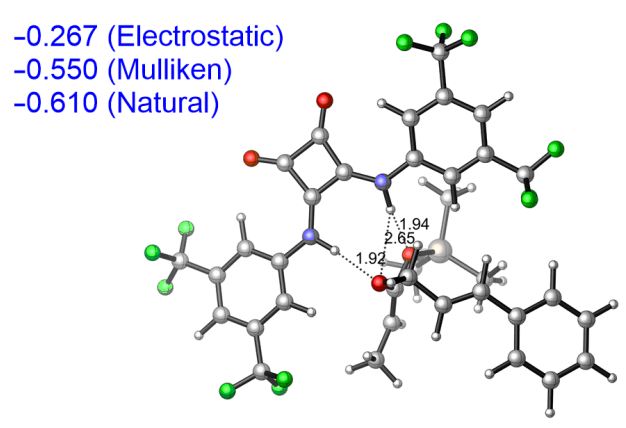

(E)-silyl ketene acetal + squaramide

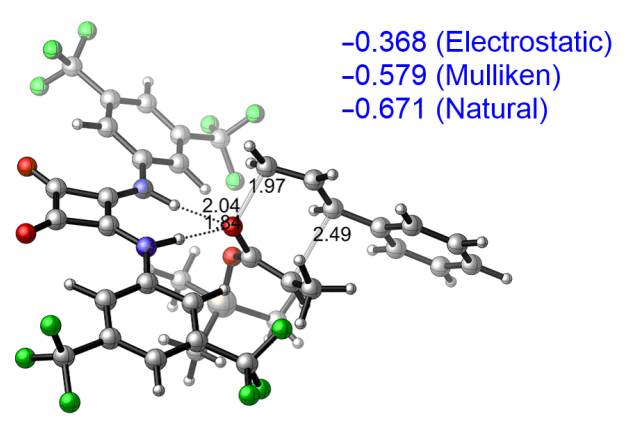

TS-(E)-squaramide-catalyzed $\left(\Delta^{\ddagger} \mathrm{G}=98.6 \mathrm{~kJ} \cdot \mathrm{mol}^{-1}\right)$

Figure 4: $\omega \mathrm{B} 97 \mathrm{X}-\mathrm{D} / 6-31 \mathrm{G}^{*}$ calculated Ph-thiourea (top) and squaramide-catalyzed (bottom) Ireland-Claisen rearrangement of 1c. Charges on allylic oxygen (blue); C-O bond-breaking and C-C bond-forming distances in TS (black); hydrogen-bond distances (black).

Table 6: Comparison of DFT-calculated interaction energies between starting silyl ketene acetal/transition state structure and catalysts.

\begin{tabular}{llll} 
Structure & $\Delta E\left(\mathrm{~kJ} \cdot \mathrm{mol}^{-1}\right)^{\mathrm{a}}$ & Structure & $\Delta E\left(\mathrm{~kJ} \cdot \mathrm{mol}^{-1}\right)^{\mathrm{a}}$ \\
\hline (E)-2c (C12) & -135.5 & $(E)-2 \mathbf{c}($ Ph-thiourea) & -91.7 \\
TS-(E)-2c (C12) & -105.0 & TS-(E)-2c (Ph-thiourea) & -61.8 \\
$(Z)-2 \mathbf{C}(\mathbf{C 1 2})$ & -112.1 & $(E)-2 \mathrm{c}$ (squaramide) & -119.2 \\
TS-(Z)-2c (C12) & -98.0 & TS-(E)-2c (squaramide) & -122.7 \\
\hline
\end{tabular}

${ }^{a}$ Calculated at $\omega \mathrm{B} 97 \mathrm{X}-\mathrm{D} / 6-31 \mathrm{G}^{*} / / \mathrm{M} 06-2 \mathrm{X} / 6-311+\mathrm{G}^{* *}$ level as a difference between electronic energy of $\mathbf{2 c}-$ catalyst (or TS-2c-catalyst) complex and sum of individual components.

a)

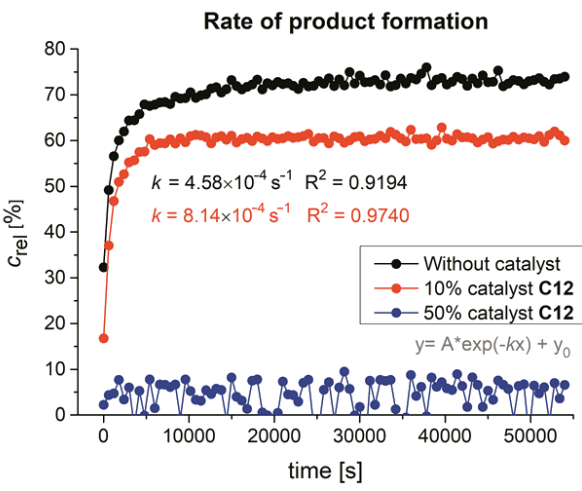

b)

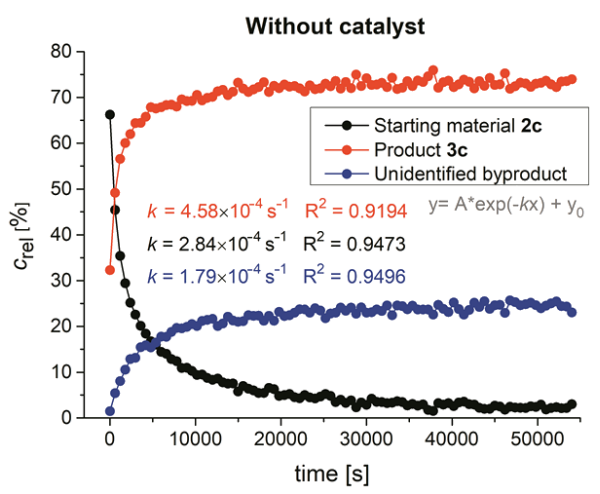

Figure 5: a) Rate of product formation; b) reaction profile without catalyst determined by ${ }^{1} \mathrm{H}$ NMR. 
parison of product formation in the presence of 0,10 , and $50 \mathrm{~mol} \%$ of catalyst C12. As can be seen, the catalyst hindered product formation and at $50 \mathrm{~mol} \%$ catalyst loading product 3c practically does not form. A reaction profile without catalyst is displayed in Figure 5b. In this case, the formation of a small amount of an unidentified byproduct was also observed. The rate constants for the uncatalyzed and catalyzed reaction are similar. The activation Gibbs energy was determined to be approximately $90 \mathrm{~kJ} \cdot \mathrm{mol}^{-1}$, which agrees well with the DFT calculated values. These kinetic measurements support the notion that H-bonding catalysts bind stronger to starting silyl ketene acetals and thus prevent it from undergoing Ireland-Claisen rearrangement. For more details, see Supporting Information File 1.

\section{Conclusion}

Chiral hydrogen-bond-donating organocatalysts such as thioureas, squaramides, or alcohols failed to catalyze the Ireland-Claisen rearrangement of silyl ketene acetals. Comparison experiments showed that increasing catalyst loading gradually slowed-down the reaction. DFT calculations using longrange corrected hybrid density $\omega$ B97X-D functional showed that thioureas and squaramides stabilize the starting ground state more than the corresponding transitions states. This fact leads to a higher activation barrier and slower reactions in the presence of hydrogen-bond donating organocatalysts. On the other hand, catalyst-free Ireland-Claisen rearrangements proceed well in green solvents such as CpOMe or under solvent-free conditions. NMR kinetic measurements supported the notion that thiourea and squaramide organocatalysts bind strongly to the starting silyl ketene acetals and prevent the Ireland-Claisen rearrangement. Further experiments towards finding more effective organocatalysts are underway in our laboratory.

\section{Experimental}

\section{A typical procedure for Ireland-Claisen rearrangement with $\mathrm{Et}_{3} \mathrm{~N}$}

Ester 1 (2.34 mmol) was added to a solution of $\mathrm{Et}_{3} \mathrm{~N}(1.6 \mathrm{~mL}$, $11.5 \mathrm{mmol})$ in dry $\mathrm{CH}_{2} \mathrm{Cl}_{2}(2.2 \mathrm{~mL})$ under a nitrogen atmosphere and the reaction mixture was cooled to $-60{ }^{\circ} \mathrm{C}$. Then, trialkyl silyl triflate $(3.7 \mathrm{mmol})$ was added dropwise, followed by addition of the organocatalyst $(10 \mathrm{~mol} \%)$ in one portion. The reaction temperature was allowed to reach ambient temperature and the reaction mixture was stirred at this temperature for $24 \mathrm{~h}$. Afterwards, the solvent was evaporated under reduced pressure and $\mathrm{Et}_{2} \mathrm{O}(5 \mathrm{~mL})$ and $1.3 \mathrm{M} \mathrm{NaOH}(7 \mathrm{~mL})$ were added to the residue. The aqueous layer was washed with $\mathrm{CH}_{2} \mathrm{Cl}_{2}$ $(3 \times 8 \mathrm{~mL})$, and then it was acidified with concentrated $\mathrm{HCl}$. The products were extracted with $\mathrm{CH}_{2} \mathrm{Cl}_{2}(3 \times 8 \mathrm{~mL})$. The organic solution was washed with water $(3 \times 12 \mathrm{~mL})$ and dried with anhydrous $\mathrm{MgSO}_{4}$. The solvent was evaporated under reduced pressure.

\section{Supporting Information}

\section{Supporting Information File 1}

Experimental procedures and characterization data for all compounds, copies of NMR spectra, details of DFT calculations.

[https://www.beilstein-journals.org/bjoc/content/ supplementary/1860-5397-15-290-S1.pdf]

\section{Acknowledgements}

This publication is the result of the project implementation 262401200025 supported by the Research \& Development Operational Program funded by the ERDF. We thank Dr. Marek Cigán for valuable discussions.

\section{ORCID ${ }^{\circledR}$ iDs}

Dominika Krištofíková - https://orcid.org/0000-0001-5081-5986 Radovan Šebesta - https://orcid.org/0000-0002-7975-3608

\section{References}

1. Ireland, R. E.; Mueller, R. H. J. Am. Chem. Soc. 1972, 94, 5897-5898. doi:10.1021/ja00771a062

2. Ireland, R. E.; Willard, A. K. Tetrahedron Lett. 1975, 16, 3975-3978. doi:10.1016/s0040-4039(00)91213-9

3. Ireland, R. E.; Wilcox, C. S. Tetrahedron Lett. 1977, 18, 2839-2842. doi:10.1016/s0040-4039(01)83088-4

4. Davies, S. G.; Fletcher, A. M.; Roberts, P. M.; Thomson, J. E.; Zammit, C. M. Chem. Commun. 2013, 49, 7037-7039. doi:10.1039/c3cc43250e

5. Krebs, A.; Kazmaier, U. Tetrahedron Lett. 1996, 37, 7945-7946. doi:10.1016/0040-4039(96)01764-9

6. Srikrishna, A.; Khan, I. A.; Babu, R. R.; Sajjanshetty, A. Tetrahedron 2007, 63, 12616-12620. doi:10.1016/j.tet.2007.10.021

7. Churcher, I.; Williams, S.; Kerrad, S.; Harrison, T.; Castro, J. L.; Shearman, M. S.; Lewis, H. D.; Clarke, E. E.; Wrigley, J. D. J.; Beher, D.; Tang, Y. S.; Liu, W. J. Med. Chem. 2003, 46, 2275-2278. doi:10.1021/jm034058a

8. Kraft, P.; Denizot, N. Eur. J. Org. Chem. 2013, 49-58. doi:10.1002/ejoc.201201318

9. Liu, D.; Yu, X.; Huang, L. Chin. J. Chem. 2013, 31, 344-348. doi:10.1002/cjoc.201201187

10. Dittrich, N.; Jung, E.-K.; Davidson, S. J.; Barker, D. Tetrahedron 2016, 72, 4676-4689. doi:10.1016/j.tet.2016.06.049

11. Tellam, J. P.; Carbery, D. R. J. Org. Chem. 2010, 75, 7809-7821. doi:10.1021/j01017124

12. Ito, H.; Taguchi, T. Chem. Soc. Rev. 1999, 28, 43-50. doi:10.1039/a706415b

13. Chai, Y.; Hong, S.-p.; Lindsay, H. A.; McFarland, C.; McIntosh, M. C. Tetrahedron 2002, 58, 2905-2928. doi:10.1016/s0040-4020(02)00164-3 
14. Welch, J. T.; Samartino, J. S. J. Org. Chem. 1985, 50, 3663-3665. doi:10.1021/jo00219a056

15. Godenschwager, P. F.; Collum, D. B. J. Am. Chem. Soc. 2008, 130, 8726-8732. doi:10.1021/ja800250q

16. Welch, J. T.; Plummer, J. S.; Chou, T. S. J. Org. Chem. 1991, 56, 353-359. doi:10.1021/jo00001a065

17. Liu, D.; Yu, X. Tetrahedron Lett. 2012, 53, 2177-2180. doi:10.1016/j.tetlet.2012.02.071

18. Kobayashi, M.; Masumoto, K.; Nakai, E.-i.; Nakai, T. Tetrahedron Lett. 1996, 37, 3005-3008. doi:10.1016/0040-4039(96)00485-6

19. Araki, K.; Welch, J. T. Tetrahedron Lett. 1993, 34, 2251-2254. doi:10.1016/s0040-4039(00)77586-1

20. Uchiyama, H.; Kawano, M.; Katsuki, T.; Yamaguchi, M. Chem. Lett. 1987, 16, 351-354. doi:10.1246/cl.1987.351

21. Koch, G.; Janser, P.; Kottirsch, G.; Romero-Giron, E. Tetrahedron Lett. 2002, 43, 4837-4840. doi:10.1016/s0040-4039(02)00864-x

22. Corey, E. J.; Lee, D. H. J. Am. Chem. Soc. 1991, 113, 4026-4028. doi:10.1021/ja00010a074

23. Seizert, C. A.; Ferreira, E. M. Chem. - Eur. J. 2014, 20, 4460-4468. doi:10.1002/chem.201304384

24. Kazmaier, U. Liebigs Ann. Recl. 1997, 285-295. doi:10.1002/jlac.199719970203

25. Burke, S. D.; Fobare, W. F.; Pacofsky, G. J. J. Org. Chem. 1983, 48, 5221-5228. doi:10.1021/jo00174a013

26. Kazmaier, U.; Krebs, A. Angew. Chem., Int. Ed. Engl. 1995, 34, 2012-2014. doi:10.1002/anie.199520121

27. Wong, K. C.; Ng, E.; Wong, W.-T.; Chiu, P. Chem. - Eur. J. 2016, 22, 3709-3712. doi:10.1002/chem.201504870

28. Moyano, A.; El-Hamdouni, N.; Atlamsani, A. Chem. - Eur. J. 2010, 16, 5260-5273. doi:10.1002/chem.200903410

29. Tantillo, D. J. Acc. Chem. Res. 2016, 49, 741-749. doi:10.1021/acs.accounts.6b00029

30. Li, G.-Q.; Gao, H.; Keene, C.; Devonas, M.; Ess, D. H.; Kürti, L. J. Am. Chem. Soc. 2013, 135, 7414-7417. doi:10.1021/ja401709k

31. Wang, J.-Z.; Zhou, J.; Xu, C.; Sun, H.; Kürti, L.; Xu, Q.-L. J. Am. Chem. Soc. 2016, 138, 5202-5205. doi:10.1021/jacs.6b01458

32. Gao, H.; Xu, Q.-L.; Keene, C.; Yousufuddin, M.; Ess, D. H.; Kürti, L. Angew. Chem., Int. Ed. 2016, 55, 566-571. doi:10.1002/anie.201508419

33. Rueping, M.; Antonchick, A. P. Angew. Chem., Int. Ed. 2008, 47, 10090-10093. doi:10.1002/anie.200803610

34. Maity, P.; Pemberton, R. P.; Tantillo, D. J.; Tambar, U. K. J. Am. Chem. Soc. 2013, 135, 16380-16383. doi:10.1021/ja4095473

35. Uyeda, C.; Jacobsen, E. N. J. Am. Chem. Soc. 2008, 130, 9228-9229. doi:10.1021/ja803370x

36. Uyeda, C.; Rötheli, A. R.; Jacobsen, E. N. Angew. Chem., Int. Ed. 2010, 49, 9753-9756. doi:10.1002/anie.201005183

37. Uyeda, C.; Jacobsen, E. N. J. Am. Chem. Soc. 2011, 133, 5062-5075. doi:10.1021/ja110842s

38. Kirsten, M.; Rehbein, J.; Hiersemann, M.; Strassner, T. J. Org. Chem. 2007, 72, 4001-4011. doi:10.1021/jo062455y

39. Ganem, B. Angew. Chem., Int. Ed. Engl. 1996, 35, 936-945. doi:10.1002/anie.199609361

40. Shanab, K.; Neudorfer, C.; Spreitzer, H. Curr. Org. Chem. 2016, 20 , 1576-1583. doi:10.2174/1385272820666160209212804

41. Tang, S.; Zhao, H. RSC Adv. 2014, 4, 11251-11287. doi:10.1039/c3ra47191h

42. Chai, J.-D.; Head-Gordon, M. Phys. Chem. Chem. Phys. 2008, 10, 6615-6620. doi:10.1039/b810189b
43. Mardirossian, N.; Head-Gordon, M. Mol. Phys. 2017, 115, 2315-2372. doi:10.1080/00268976.2017.1333644

\section{License and Terms}

This is an Open Access article under the terms of the Creative Commons Attribution License (http://creativecommons.org/licenses/by/4.0). Please note that the reuse, redistribution and reproduction in particular requires that the authors and source are credited.

The license is subject to the Beilstein Journal of Organic Chemistry terms and conditions:

(https://www.beilstein-journals.org/bjoc)

The definitive version of this article is the electronic one which can be found at:

doi:10.3762/bjoc. 15.290 